\title{
Peran Sanggar Seni Pemuda Edi Peni Dalam Pelestarian Budaya Lokal Di Desa Hadiluwih Kecamatan Ngadirojo Kabupaten Pacitan
}

\author{
Aziz Mei Kurnianto, Deditiani Tri Indrianti, Lutfi Ariefianto \\ Program Studi Pendidikan Luar Sekolah, Jurusan Ilmu Pendidikan, Fakultas Keguruan dan Ilmu Pendidikan \\ Universitas Jember. Jl. Kalimantan No. 37, TegalBoto, Jember 62811, Indonesia \\ Email: kurniantoaziz22@gmail.com,
}

\begin{abstract}
Abstrak
Generasi muda merupakan penggerak utama dalam proses pelestarian budaya. Pentingnya menjaga dan melestarikan kebudayaan lokal yang bertujuan untuk menghindarkan dari kepunahan. Sanggar Seni mempunyai peran yang sangat besar dalam proses melindungi kebudayaan lokal yaitu peran untuk menjaga dan melindungi kebudayaan local. Hasil dari penelitian ini diharapkan dapat dijadikan sebagai bahan informasi, perbandingan, dan referensi literatur bagi peneliti lain. Penelitian ini merupakan penelitian deskriptif dengan menggunakan pendekatan kualitatif. Penentuan lokasi penelitian ini menggunakan metode purposive area yaitu di Sanggar Seni Pemuda Edi Peni Desa Hadiluwih Kecamatan Ngadirojo Kabupaten Pacitan. Teknik menentukan informan penelitian menggunakan metode snowball sampling. Metode pengumpulan data yang digunakan terdiri dari metode: wawancara, observasi, dan dokumentasi. Teknik pengolahan data yakni perpanjang penelitian, penigkatan ketekunan, dan triangulasi menggunakan triangulasi sember. Analisis data yang akan digunakan yaitu pengumpulan data, reduksi data, melakukan display data atau penyajian data, dan mengambil kesimpulan dan verifikasi.
\end{abstract}

Kata Kunci: Budaya, Sanggar Seni, dan Peran Sanggar Seni.

\section{The Role Of The Edi Peni Youth Art Studio In The Preservation Of Local Culture In Hadiluwih Village, Ngadirojo, Pacitan}

\begin{abstract}
The young generation is the main driver in the process of cultural preservation. The importance of maintaining and preserving local culture which aims to avoid extinction. Sanggar Seni has a very big role in the process of protecting local culture, namely the role of protecting and protecting local culture, therefore the researcher took the following problem how the role of Pemuda Edi Peni Art Studio in preserving local culture in Hadiluwih Village, Ngadirojo District, Pacitan Regency ?. The results of this study are expected to be used as material for information, comparison and literature references for other researchers. This research is a descriptive study using a qualitative approach. Determining the location of this study using a purposive area method, namely at the Pemuda Edi Peni Art Studio in Hadiluwih Village, Ngadirojo District, Pacitan Regency. The technique of determining research informants using the snowball sampling method. The data collection method used consists of methods: interviews, observation, and documentation. Data processing techniques are extending research, increasing persistence, and triangulation using semangular triangulation. Analysis of data to be used is data collection, data reduction, displaying data or presenting data, and drawing conclusions and verification.
\end{abstract}

Keywords: Culture, Art Studio, and the Role of Art Studi 


\section{Learning Community: Jurnal Pendidikan Luar Sekolah, 3 (2), September 2019 - 61 Aziz Mei Kurnianto}

\section{PENDAHULUAN}

Hadiluwih merupakan sebuah desa yang berada di Kecamatan Ngadirojo, Kabupaten Pacitan, Jawa Timur yang memiliki enam dusun. Desa Hadiluwih mempunyai luas wilayah seluas 329,01 ha dan memiliki jumlah penduduk sekitar 2.301 jiwa. Desa Hadiluwih memiliki kekayaan dan keanekaragaman budaya lokal yang patut untuk terus dilestarikan keberadaanya, budaya lokal tersebut adalah seni tari Kethek Desa Hadiluwih juga mempunyai Sanggar Seni yang dapat dijadikan sebagai tempat melestarikan budaya lokal, Sanggar tersebut adalah Sanggar Seni Pemuda Edi Peni. Banyaknya kasus kebudayaan lokal Indonesia yang mulai hilang/punah maka diperlukan pelestarian budaya lokal supaya kebudayaan tetap lestari keberadaannya. Budaya merupakan identitas suatu bangsa yang patut untuk terus dilestarikan keberadaannya. Pada era sekarang ini para generasi muda sudah mulai enggan untuk melestarikan budaya lokal asli dari daerahnya. Generasi muda lebih menyukai berbagai macam kebudayaan dari luar negeri dibandigkan dengan kebudayaan negeri sendiri.

Hal ini dikarenakan gaya hidup generasi muda lebih rentan dan lebih mudah menerima hal-hal yang dianggap sebagai hal baru tidak terkecuali kebudayaan. Generasi muda merupakan penggerak utama dalam proses pelestarian budaya. Pemuda mempunyai peran yang penting untuk tetap menjaga dan melestarikan kebudayaan asli Indonesia agar terhindar dari kepunahan. Berbagai macam aktivitas dalam upaya pelestarian kebudayaan lokal mulai muncul dari berbagai kalangan. Tidak terkecuali dari generasi muda, cara untuk melestarikan budaya bermacam-macam baik secara langsung maupun tidak langsung, salah satunya dengan mendirikan Sanggar Seni.

Peran Sanggar Seni sangat dibutuhkan untuk terus menjaga dan melestarikan budaya lokal, agar budaya lokal tidak punah dan juga bisa dikenal masyarakat luas. Banyak sekali bentuk atau upaya pelestarian budaya local yang dilakukan oleh Sanggar Seni salah satunya adalah melakukan pelatihan-pelatihan tari tradisional dan juga ikut mementaskan budaya lokal dalam festival-festival, seperti festival budaya yang diadakan oleh pemerintah disetiap tahunnya. Tetapi pada era sekarang ini kurangnya kecintaan masyarakat khususnya pemuda terhadap kebudayaan lokal dari daerah mereka tinggal. Pemuda lebih menyukai berbagai macam kebudayaan dari luar negeri dibandingkan dengan kebudayaan dari negeri sendiri

\section{METODE}

Penelitian ini merupakan jenis penelitian deskriptif dengan pendekatan kualitatif. penelitian ini selama 5 bulan, dimulai dari bulan November 2018 sampai dengan bulan Maret 2019, dengan rincian 1 bulan persiapan, 3 bulan penelitian dan revisi, 1 bulan penyelesaian. Di Desa Hadiluwih Kecamatan Ngadirojo Kabupatren Pacitan sebagai daerah yang dipilih untuk tempat penelitian dengan menggunakan teknik purposive area . Sedang untuk engumpulan data menggunakan wawancara, observasi, dokumentasi.

Pengumpulan data dalam penelitian ini, penentuan subjek penelitian menggunakan teknik snowball sampling. data selanjutnya dengan teknik pengolahan data yakni perpanjang penelitian, penigkatan ketekunan, dan triangulasi menggunakan triangulasi sember. Analisis data yang akan digunakan dalam penelitian ini yaitu pengumpulan data, reduksi data, melakukan display data atau penyajian data, dan mengambil kesimpulan dan verifikasi.

\section{HASIL DAN PEMBAHASAN}

Dari pengumpulan dan pemaparan data diketahui bahwa adanya peran Sanggar Seni Pemuda Edi Peni dalam pelestarian budaya lokal. Fugsi Sanggar Seni Edi Peni berperan pada program pelestarian budaya lokal di Desa Hadiluwih Kecamatan Ngadirojo Kabupaten Pacitan yang dikatakan berhasil karena pihak Sanggar Seni telah melakukan tugasnya sebagai wadah untuk pelestarian dan juga tempat menjaga kebudaya lokal. Proses pelestarian dan menjaga kebudayaan lokal yang dilakukan oleh Sanggar Seni Pemuda Edi Peni adalah dengan cara melibatkan masyarakat sekitar 


\section{Learning Community: Jurnal Pendidikan Luar Sekolah, 3 (2), September 2019 - 62}

Aziz Mei Kurnianto

khususnya pemuda untuk ikut langsung melestarikan budaya lokal dan juga bekerja sama dengan pihak sekolah-sekolah yang berada disekitar Sanggar Seni.

Pada tahap pelestarian budaya local Sanggar Seni sudah melakukan beberapa langkah untuk tetap mengajarkan kebudayaan lokal kepada warga belajarnya yaitu melalui pelatihan, pementasan, dan literasi budaya dimana Sanggar Seni Pemuda Edi Peni sudah melakukan tiga hal tersebut dan dianggap sangat penting dalam membantu berjalanya program pelestarian budaya lokal yang dilakukan Sanggar Seni Pemuda Edi Peni. Untuk pelatihanya sendiri pihak Sanggar Seni mengajarkan budaya kepada anak-anak dari jenjang SD, SMP, SMA, sampai dewasa yang dilakukan seminggu sekali dan akan ditambah waktunya jika akan ada festivial-festival kesenian.

Pelatihan seni yang dilakukan oleh pihak Sanggar Seni Pemuda Edi Peni dengan mengajarkan tari-tarian lokal seperti tari Trdaksiten kepada pemuda dengan cara menayangkan video-video tari yang bertujuan untuk merangsang mereka untuk mau mempelajari tari. Dan untuk pementasan budaya lokal Sanggar Seni telah mengikuti berbagai festival di daerah maupun di luar daerah diantaranya FKKT (Festival Kesenian Kawasan Timur), FLSN (Festival Lomba Seni Nasional), O2SN (Olimpiade Olahraga Siswa Nasional), dan HUT (Hari Ulang Tahun) Kabupaten Pacitan.

Sedangkan proses literasi yang dilakukan oleh Sanggar Seni adalah dengan cara menayangkan video-video tari dan membari pengetahuan mengenai budaya local dengan cerita yang bertujuan untuk menambah pengetahuan warga belajar mengenai kebudayaan lokal yang di pelajari di Sanggar Seni Pemuda Edi Peni. Pementasan kesenian adalah salah satu cara yang dilakukan oleh Sangar Seni Pemuda Edi Peni untuk bersosialisasi dan menunjukkan eksistensi budaya lokal seperti kebudayaan Oglor, Kethek Ogleng, dan tari Tedaksiten dan lain sebagainya yang sehubungan dengan cara pengembangan seni agar dapat dikenal dan dinikmati masyarakat luas yang bertujuan untuk tetap melestarikan bebudayaan lokal tersebut.
Seperti yang dilakukan Sanggar Pemuda Edi Peni yakni melibatkan langsung masyarakat khususnya pemuda dari jenjang SD, SMP, SMA, sampai dewasa untuk ikut langsung dalam pementasan budaya local mulai dari latihan, pembuatan kostum, tata rias, menjadi peserta sampai menjadi crew dalam sebuah pementasan budaya lokal. Sanggar Seni Pemuda Edi Peni telah banyak sekali menampilkan atau mementaskan kebudayaan lokal seperti tari Tedaksiten dalam festival-festival di dalam maupun di luar daerah seperti FKKT (Festival Kesenian Kawasan Timur), FLSN (Festival Lomba Seni Nasional).

Sanggar Seni Pemuda Edi Peni dikatakan sudah berperan pada program pelestarian budaya lokal di Desa Hadiluwih Kecamatan Ngadirojo Kabupaten Pacitan, karena pihak Sanggar Seni Pemuda Edi Peni sudah menerapkan peran dari Sanggar Seni yaitu tempat pelestarian dan juga tempat menjaga kebudayaan lokal. Kedua hal tersebut sudah dilakukan oleh Sanggar Seni Pemuda Edi Peni yang berada di Desa Hadiluwih, seperti yang dikemukakan oleh Pratiwi dalam Priatna (2017: 36), dalam paparanya menyebutkan bahwa Sanggar Seni memiliki peran yang sangat penting dalam sebuah upaya pelestarian budaya lokal yang terbagi menjadi dua bentuk. Adapun bentuk yang dimaksud: 1) Bentuk pelestarian, menjaga, pemilihan, perencanaan, dan pelaksanaan; 2) Masyarakat secara partisipasional, dengan tujuan agar kesenian lokal yang awalnya lemah dan membutuhkan dukungan yang kompleks bisa berdiri secara mandiri.

Dalam penelitian ini hanya membahas dua bentuk peran dari Sanggar Seni yaitu bentuk pelestarian dan menjaga budaya, karena kedua hal tersebut merupakan hal yang sangat penting yang harus dijalankan oleh Sanggar Seni. Kedua hal tersebut sangat penting dalam upaya Sanggar Seni untuk melestarikan kebudayaan lokal.

Pelestarian kebudayaan lokal yang dilakukan di Sanggar Seni Pemuda Edi Peni dengan melibatkan masyarakat sekitar Sanggar Seni khususnya pemuda dan memaskukkan seni ke dalam ekstrakurikuler di sekolah- sekolah yang berada disekitar sanggar, seperti yang disampaikan Koentjaraningrat dalam Priatna (2017: 36), bahwa suatu pelestarian budaya adalah suatu 


\title{
Learning Community: Jurnal Pendidikan Luar Sekolah, 3 (2), September 2019 - 63
}

\author{
Aziz Mei Kurnianto
}

sistem yang besar yang dilakukan Sanggar Seni dan melibatkan masyarakat dengan masuk ke dalam subsistem kemasyarakatan serta memiliki komponen yang saling terhubung. Pesetarian budaya lokal yang dilakukan oleh Sanggar Seni Pemuda Edi Peni meliputi tiga hal yaitu pelatihan, pementasan, dan literasi seperti yang kemukakan oleh Widjaja dalam Ashar (2014: 15), mengartikan pelestarian sebagai kegiatan atau yang dilakukan secara terus menerus, terarah dan terpadu dengan pelatihan, pementasan, dan literasi budaya guna mewujudkan tujuan tertentu yang mencerminkan adanya sesuatu yang tetap dan abadi, bersifat dinamis, luwes, dan selektif. Mengenai pelestarian budaya lokal adalah mempertahankan nilai seni budaya masyarakat, nilai tradisional dengan mengembangkan perwujudan yang bersifat dinamis, luwes dan selektif, serta menyesuaikan dengan situasi dan kondisi yang selalu berubah dan berkembang ditempat budaya tersebut berada.

Pelatihan yang dilakukan oleh Sanggar Seni Pemuda Edi Peni sendiri yaitu bertujuan untuk menambah kemampuan dan keterampilan warga belajar dibidang seni. Seperti yang dikekemukakan oleh Sagala (2003:21), metode latihan (drill) atau metode training merupakan suatu cara mengajar yang baik untuk menanamkan kebiasaankebiasaan tertentu, selain itu sebagai sarana untuk memperoleh suatu ketangkasan, ketepatan, kesempatan, dan keterampilan. Sangar Seni lebih menekankan pada pelatihan tari karena pelatihan merupakan bagian dari pendidikan yang menyangkut proses belajar untuk memperoleh dan meningkatkan keterampilan di luar sistem pendidikan yang berlaku, dalam waktu yang relatif singkat, dan dengan menggunakan metode yang lebih mengutamakan praktik daripada teori (Instruksi Presiden No. 15 tahun 1974).Sanggar Seni Pemuda Edi Peni melakukan pelatihan budaya lokal dengan mengajarkan seni seperti tari-tarian kepada warga belajar khususnya anak-anak dan pemuda. Sanggar Seni Pemuda Edi Peni mengadakan ekstrakurikuler di sekolah mulai dari jenjang SD, SMP, sampai dengan SMA. Pelatihan tari yang dilakukan di Sanggar Seni Pemuda Edi Peni sendiri bertujuan untuk menanamkan kebiasaan dan menambah keterampilan warga belajar dibidang seni kepada pemuda mengenai tarian-tarian daerah, agar pemuda mengerti mengenai seluk beluk kebudayaan lokal dan juga hafal setiap gerakan- gerakan tari.

Selanjutnya adalah pementasan, pementasan yang dilakukan oleh Sanggar Seni Pemuda Edi Peni yaitu bertujuan mengenalkan budaya kepada masyarakat luas seperti yang disampaikan oleh Setyawati dalam Salsabila (2015: 13), sanggar adalah suatu wadah, tempat atau perkumpulan baik individu ataupun kelompok yang pada umumnya program serta tujuan demi munculnya ide-ide baru, kemudian dikembangkan sehingga hasilnya dapat disampaikan pada masyarakat umum dan diterima serta dapat dinikmati masyarakat. Jadi Sanggar Seni merupakan tempat untuk mengelola kesenian dan kemudian disampaikan kepada masyarakat dengan cara dipentaskan. Pementasan dapat dilakukan kapan saja dan dimana saja baik diacara resmi maupun tidak resmi.

Seperti yang dikekemukakan oleh Susetyo dalam Ela (2016: 23), seni pertunjukan/pementasan budaya adalah sebuah ungkapan budaya, wahana untuk menyampaikan nilai-nilai budaya dan perwujudan norma-norma, estetik-artistik yang berkembang sesuai zaman, dan wilayah dimana bentuk seni pertunjukan itu tumbuh dan berkembang. Dengan mementaskan budaya lokal pada festival-festival daeran maupun luar daerah dan melibatkan langsung masyarakat khususnya pemuda dan diharapkan dapat menyampaikan nilai- nilai luhur dari suatu budaya.

Untuk pementasan budaya lokal Sanggar Seni memulai dari latihan, pembuatan kostum, rias, menjadi peserta sampai jadi crew dalam pementasan. Sanggar Seni Pemuda Edi Peni telah banyak sekali menampilkan kebudayaan lokal dalam festival-festival di dalam maupun di luar daerah seperti FKKT (Festival Kesenian Kawasan Timur), O2SN (Olimpiade Olahraga Siswa Nasional), HUT (Hari Ulang Tahun) Kabupaten Pacitan, dan upacara adat. Literasi yang dilakukan oleh Sanggar Seni Pemuda Edi Peni adalah mengajarkan tarian jawa kepada warga belajarnya mulai dari anakanak SD sampai SMA dan seterusnya dengan 


\title{
Learning Community: Jurnal Pendidikan Luar Sekolah, 3 (2), September 2019 - 64
}

\author{
Aziz Mei Kurnianto
}

cara menayangkan video-video tarian kepada warga belajar.

Diharapkan dengan adanya tayangan video mengenai tarian lokal tersebut warga belajar Sanggar Seni Pemuda Edi Peni dapat menyimak serta mempelajarinya, serta menciptakan gerak tari sendiri, memberikan motivasi dan pengetahuan tentang seni dengan cerita. Seperti yang disampaikan oleh Hartati dalam Solihat (2017), Literasi merupakan kemampuan memahami, mengelola, dan menggunakan informasi dalam berbagai konteks.

Dalam hal ini literasi merupakan kemampuan memahami artinya memahami setiap pelajaran-pelajaran yang diajarkan di dalam Sanggar Seni seperti memahami setiap gerakan-gerakan tari, memahami makna dari sebuah tarian. Sanggar Seni Pemuda Edi Peni sudah melakuan proses literasi budaya kepada warga belajarnya dari mengajarkan taritarian khususnya tarian jawa kepada anakanak SD dan jenjang seterusnya dengan cara menayangkan video-video tarian kepada warga belajar supaya warga belajar tertarik untuk ikut memainkan kesenian tersebut, serta tutor mengajarkan kepada warga belajarnya untuk menciptakan gerak tari sendiri, dan memberikan motivasi dan pengetahuan tentang seni dengan cerita.

\section{SIMPULAN}

Berdasarkan analisis data maka dapat disimpulkan bahwa Sanggar Seni Pemuda Edi Peni telah berperan sangat baik dalam pelestarian budaya lokal di Desa Hadiluwih Kecamatan Ngadirojo Kabupaten Pacitan. Peran dari Sanggar Seni Pemuda Edi Peni sendiri adalah tempat untuk pelestarian dan juga tempat menjaga kebudayaan khususnya budaya lokal. Pada proses pelestarian yang dilakukan Sanggar Seni Pemuda Edi Peni adalah melibatkan langsung masyarakat dalam sistem pelestarian tersebut dan bekerjasama dengan sekolahsekolah disekitar Sanggar Seni Pemuda Edi Peni.

Dengan tujuanya untuk memasukan pendidikan seni tari ke dalam ekstrakurikular sekolah tersebut, dan dalam menjaga budaya, Sanggar Seni Pemuda Edi Peni melakukan beberapa upaya untuk tetap mempertahankan budaya lokal Kethek Ogleng, Oglor, dan tari Tedaksiten diantaranya dengan melakukan pelatihan, pementasan, dan literasi budaya.Pelatihan yang dilakukan Sanggar Seni Pemuda Edi Peni sendiri adalah dengan melibatkan warga sekitar khususnya pemuda dan anakanak dari jenjang SD, SMP, SMA, sampai dewasa dengan mengajarkan tari-tarian kepada mereka.

Pelatihan tari yang dilakukan di Sanggar Seni Pemuda Edi Peni sendiri bertujuan untuk menanamkan kebiasaan kepada mereka mengenai tarian-tarian daerah. Sedangkan untuk pementasan budaya lokal Sanggar Seni Pemuda Edi Peni menampilkan kebudayaan lokal dalam festival-festival di event daerah maupun event nasional seperti FKKT (Festival Kesenian Kawasan Timur), FLSN (Festival Lomba Seni Nasional), O2SN (Olimpiade Olahraga Siswa Nasional), HUT (Hari Ulang Tahun) Kabupaten Pacitan. Untuk kontribusi Sanggar Seni Edi Peni dapat dikatakan sangat besar di Kabupaten Pacitan karena Sanggar Seni Pemuda Edi Peni selalu ikut dalam HUT (Hari Ulang Tahun) Kabupaten Pacitan setiap tahunnya dan acara- acara adat lainnya. Untuk literasi budaya Sanggar Seni Pemuda Edi Peni mengajarkan budaya lokal kepada warga belajarnya dengan cara menayangkan videovideo tari, dengan buku, dengan bercerita mengenai kebudayaan lokal

\section{DAFTAR PUSTAKA}

Priatna, Yola. 2017. Melek Informasi Sebagai Kunci Keberhasilan Pelestarian Budaya Lokal. Jurnal Vol. 1 No.2 Tahun 2017.

Ashar, Pratama W. 2014. Upaya PeletarianBudaya Lokal Oleh Pusat Kegiatan Belajar Mengajar (PKBM) Dewi Fortuna Melalui Pelatihan Pegkaderan Berbasis Budaya. Skripsi Pendidikan Luar Sekolah Universitas Negri Yogyakarta.

Instruksi Presiden No. 15 tahun 1974 tentang pelatihan.https://peraturan.bkpm.go. id/idih/serfilesbatang/InPres 15197 4.pdf [Diakses pada tanggal 1 juni 2018].

Salsabila, Kania Rizki. 2015. Peranan Sanggar Tari Kaloka Terhadap Perkembangan Tari Di Kota 
Learning Community: Jurnal Pendidikan Luar Sekolah, 3 (2), September 2019 - 65 Aziz Mei Kurnianto

Pekalongan. Skripsi Fakultas Bahasa

Dan Seni Universitas Negeri

Semarang.

Ela, 2016. Partisipasi Pemuda Dalam

Program Karang Taruna Di

Bidang Kesenian Di Desa

Tanjungharjo Kecamatan Nanggulan

Kabupaten Kulon Progo. Skripsi

Program Studi Pendidikan Luar

Sekolah Universitas Negri

Yogyakarta.

Solihat, Ilmi. 2018. Literasi Cerita Anak Dalam Keluarga Berperan Sebagai Pembelajaran Pembentuk Karakter Anak Sekolah Dasar. Jurnal JPSD Vol. 4 No. 2, September 2018. 